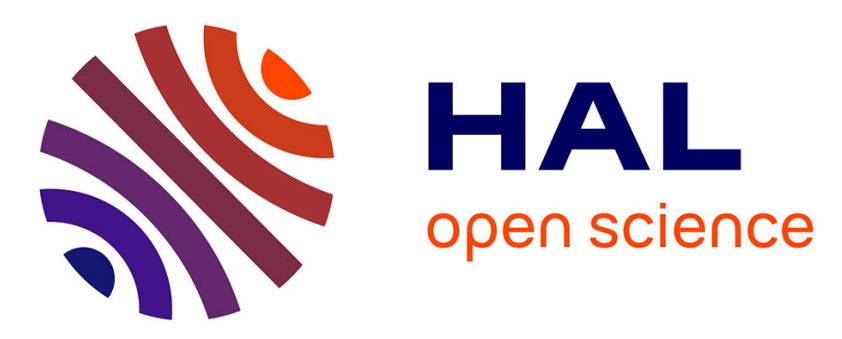

\title{
Supramolecular Polymerization of Triarylamine-Based Macrocycles into Electroactive Nanotubes
}

Flavio Picini, Susanne Schneider, Odile Gavat, Andreas Vargas Jentzsch, Junjun Tan, Mounir Maaloum, Jean-Marc Strub, Shoichi Tokunaga, Jean-Marie Lehn, Emilie Moulin, et al.

\section{To cite this version:}

Flavio Picini, Susanne Schneider, Odile Gavat, Andreas Vargas Jentzsch, Junjun Tan, et al.. Supramolecular Polymerization of Triarylamine-Based Macrocycles into Electroactive Nanotubes. Journal of the American Chemical Society, 2021, 143 (17), pp.6498-6504. 10.1021/jacs.1c00623 . hal-03418798

\section{HAL Id: hal-03418798 \\ https://hal.science/hal-03418798}

Submitted on 8 Nov 2021

HAL is a multi-disciplinary open access archive for the deposit and dissemination of scientific research documents, whether they are published or not. The documents may come from teaching and research institutions in France or abroad, or from public or private research centers.
L'archive ouverte pluridisciplinaire HAL, est destinée au dépôt et à la diffusion de documents scientifiques de niveau recherche, publiés ou non, émanant des établissements d'enseignement et de recherche français ou étrangers, des laboratoires publics ou privés. 


\title{
Supramolecular Polymerization of Triarylamine-based Macrocycles into Electroactive Nanotubes
}

\author{
Flavio Picini, ${ }^{\ddagger \mathrm{a}]}$ Susanne Schneider, ${ }^{\lceil[\mathrm{a}, \mathrm{b}]}$ Odile Gavat, ${ }^{[\mathrm{a}]}$ Andreas Vargas Jentzsch, ${ }^{[\mathrm{a}]}$ Junjun Tan, ${ }^{[\mathrm{a}]}$ \\ Mounir Maaloum, ${ }^{[a]}$ Jean-Marc Strub, ${ }^{[c]}$ Shoichi Tokunaga, ${ }^{[a, b]}$ Jean-Marie Lehn, ${ }^{* b]}$ Emilie Moulin ${ }^{[a]}$ \\ and Nicolas Giuseppone*[a]
}

[a] SAMS Research Group, Université de Strasbourg, CNRS, Institut Charles Sadron UPR22, 67000 Strasbourg, France [b] Laboratoire de Chimie Supramoléculaire, Institut de Science et d'Ingénierie Supramoléculaires, Université de Strasbourg, 8 allée Gaspard Monge, 67000 Strasbourg, France

[c] LSMBO, Institut Pluridisciplinaire Hubert Curien, CNRS UMR7178, Université de Strasbourg, 67000 Strasbourg, France

Supporting Information Placeholder

\begin{abstract}
A $S_{6}$-symmetric triarylamine-based macrocycle (i.e. hexaaza[16]para-cyclophane), decorated with six lateral amide functions, is synthesized by a convergent and modular strategy. This macrocycle is shown to undergo supramolecular polymerization in $o$-dichlorobenzene, and its nanotubular structure is elucidated by a combination of spectroscopy and microscopy techniques, together with X-ray scattering and molecular modelling. Upon sequential oxidation, a spectroelectrochemical analysis of the supramolecular polymer suggests an extended electronic delocalization of charge carriers both within the macrocycles (through bond) and between macrocycles along the stacking direction (through space).
\end{abstract}

\section{INTRODUCTION}

Supramolecular polymerization ${ }^{1-5}$ of $\pi$-conjugated molecules has become a powerful method to access soft and reconfigurable materials for organic electronics ${ }^{6-10}$ and photonics. ${ }^{11-13}$ It is now well-established that the functional properties and efficiencies of such soft materials in devices are strongly dependent on their morphology at all scales. ${ }^{14-16} \mathrm{We}$ recently became interested in exploring the possibility to grow supramolecular polymers from an intriguing class of conjugated macrocycles known as hexaaza[16]paracyclophanes. These cyclic oligoarylamine molecules have been first synthesized ten years ago by Ito and Tanaka, ${ }^{17}$ who demonstrated their multi-redox activity together with the presence of fully delocalized charges over the macrocycle by hole-doping. Studies by other groups on this macrocyclic core confirmed its very attractive magnetic and conducting properties. ${ }^{18-21}$ We envisionned that, if such macrocycles were stacked into axially aligned supramolecular polymers, delocalization of charges may take place both through bonds within the molecular ring structure, and through space between macrocycles. Such an electronic configuration would lead to fully delocalized nanotubular structures, with the potential to access supramolecular solenoids. Based on our previous demonstration that monotriarylamine molecules can undergo supramolecular polymerization when substituded by lateral amide groups (e.g. TATA in Figure 1a),,$^{22-25}$ we designed a hexaaza[16]paracyclophane hexa-amide in order to probe its potential selfassembly, and to evaluate its optoelectronic properties as a monomer and as a supramolecular polymer (Figure 1b).

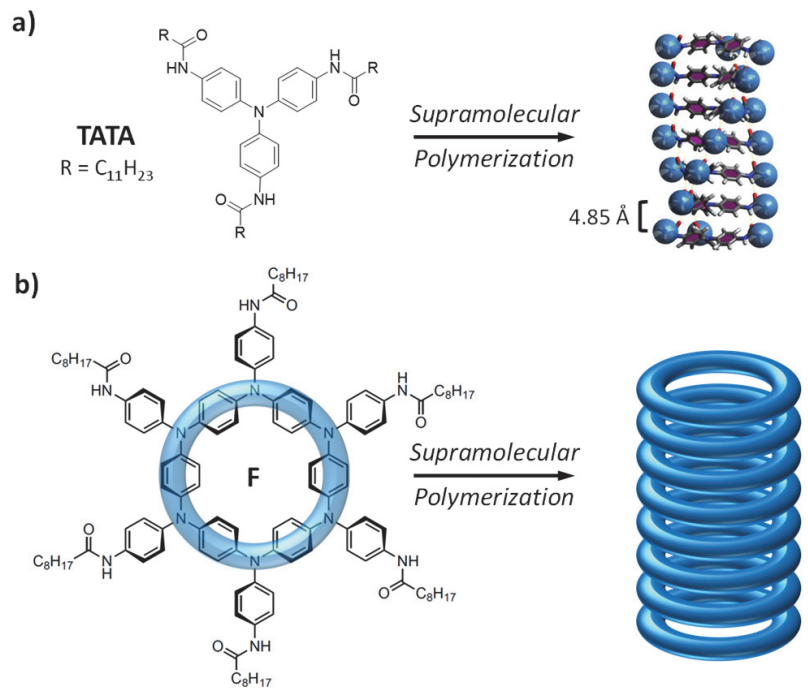

Figure 1. a) Previous works: molecular structure of a $C_{3}$-symmetric triarylamine tris-amide (TATA) and its supramolecular polymerization into a 1D helical fibril. ${ }^{22,25}$ (Reproduced from $J$. Am. Chem. Soc. 2014, 136, 11382. Copyright 2014 American Chemical Society). b) This work: $S_{6}$-symmetric macrocyclic hexaaza[16]para-cyclophane hexa-amide (F), and its axial supramolecular polymerization into a $3 \mathrm{D}$ nanotubular structure.

\section{RESULTS AND DISCUSSION}

Our study started with the chemical synthesis of triarylamine-based macrocycle F (Figure $1 \mathrm{~b}$ and Scheme 1), which was successfully obtained by designing an entirely new synthetic strategy compared to those used for the simpler hexaaza[16]para-cyclophanes previously described in the literature. ${ }^{17,18}$ Indeed, the generic reactions developed so far to access unsubstituted hexaaza[16]paracyclophane proved to fail in our hands with the presence of peripheral amide groups. In contrast, our newly designed strategy, centered on key intermediate $\mathbf{C}$, appears efficient, convergent, and modular enough to access in principle various symmetric and unsymmetric functional macrocycles of that family. 


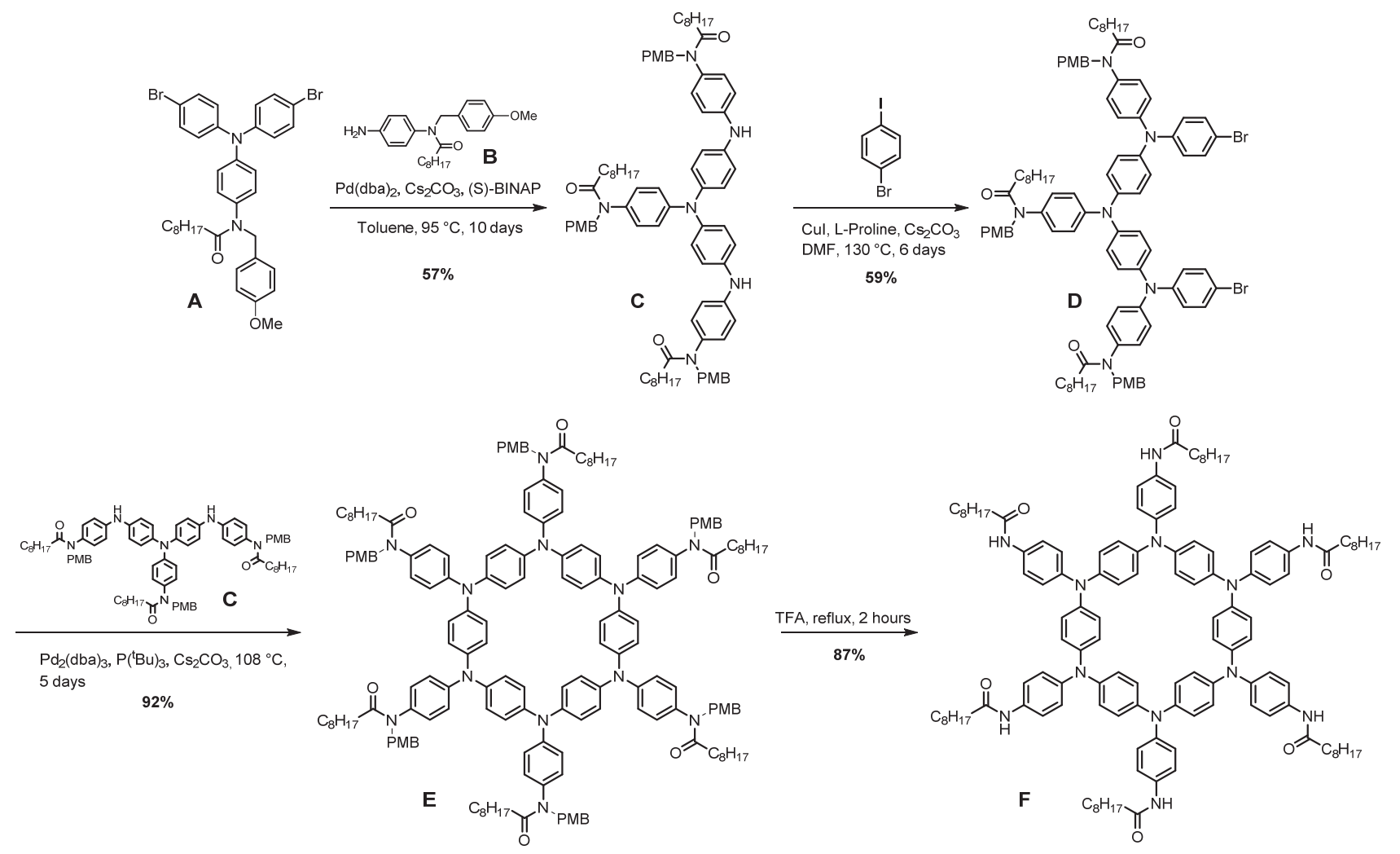

Scheme 1. Synthetic pathway developed to access triarylamine-based macrocycle $\mathbf{F}(\mathrm{PMB}=p$-methoxybenzyl).

The sequence described in Scheme 1 requires triarylamine derivative $\mathbf{A}$ and aniline $\mathbf{B}$ as starting materials. Precursor A was synthetized from commercially available bis(4bromophenyl)amine 1 (Scheme S1), according to the following four-step sequence: 1) Aromatic nucleophilic substitution with 4fluoro-1-nitrobenzene; 2) reduction of the nitro group with tin chloride; 3 ) reductive amination with $p$-methoxybenzaldehyde to introduce PMB protecting groups; and 4) acylation of the resulting primary amine with nonanoyl chloride. This synthesis was satisfactorily performed on the gram scale with $\sim 41 \%$ yield over the whole sequence. Precursor B was synthesized from $p$ nitroaniline (Scheme S2), according to the following three-step sequence: 1) reductive amination with $p$-methoxybenzaldehyde to introduce the PMB protecting group; 2) acylation with nonanoyl chloride; and 3) final reduction of the nitro group mediated by tin chloride. The gram scale synthesis of this sequence afforded precursor $\mathbf{B}$ in an overall yield of $\sim 36 \%$. Compounds $\mathbf{A}$ and $\mathbf{B}$ were then coupled in Buchwald-Hartwig conditions using bis(dibenzylideneacetone) palladium $(0)$ as catalyst to provide key diamine $\mathbf{C}$ with a good yield of $57 \%$. This compound was then reacted with 1-bromo-4-iodobenzene in a copper-catalyzed modified Ullmann coupling to yield dibromo derivative D (59\%). We then turned to the macrocyclisation step, at the core of this synthetic strategy, and which consists in the heterocoupling of compounds $\mathbf{C}$ and $\mathbf{D}$ in order to produce the fully substituted hexaaza[16]para-cyclophane, while avoiding oligomerization products. Very satisfactorily, Buchwald-Hartwig conditions using tris(dibenzylideneacetone)dipalladium $(0)$ as catalyst, tri-tertbutylphosphine as ligand, and cesium carbonate as base afforded the desired macrocycle $\mathbf{E}$ in an excellent yield of $92 \%$ after recrystallization. Finally, the last step consisted in the simultaneous deprotection of the six PMB groups. While the common PMB deprotection method using DDQ proved ineffective because of the presence of multiple redox centers on the macrocyle, ${ }^{26,27}$ heating of compound $\mathbf{E}$ in pure TFA at reflux led to its complete debenzylation within 2 hours. After several precipitations, hexaamide macrocycle $\mathbf{F}$ was obtained in a good yield of $87 \%$. The expected chemical structure and the purity of the final macrocycle were confirmed by NMR spectroscopy and MALDI-TOF analysis (see SI for detailed synthetic protocols and characterizations).

We subsequently investigated the propensity of macrocycle $\mathbf{F}$ to self-assemble, possibly into supramolecular nanotubes, by taking advantage of its six peripheral amide groups. For that, we performed TEM, SEM, and AFM microscopy studies in order to compare the morphologies of the aggregates obtained from protected macrocycle $\mathbf{E}$ on the one hand, and from its deprotected analogue $\mathbf{F}$ on the other hand. AFM imaging of protected macrocycle $\mathbf{E}$ on HOPG showed the presence of large organized monolayers with a height of $\approx 6 \AA$ (corresponding to the thickness of a single macrocycle which lies parallel to the surface) (Figure 2a, 3a, and S9). The two-dimensional fast Fourier transform (FFT) of these monolayers revealed a characteristic hexagonal pattern with a radial distance of $5.6 \mathrm{~nm}$ (Figure 2b). AFM magnification of this hexagonal pattern is in very good agreement with our molecular modelling showing a tiling of macrocycles which interdigitate two pairs of their alkyl chains in order to form the edges of the hexagons (Figure 2c). This proposed pattern is also in agreement with the measured $5.6 \mathrm{~nm}$ distance between the large holes at the centers of the hexagons (Figure S9). 

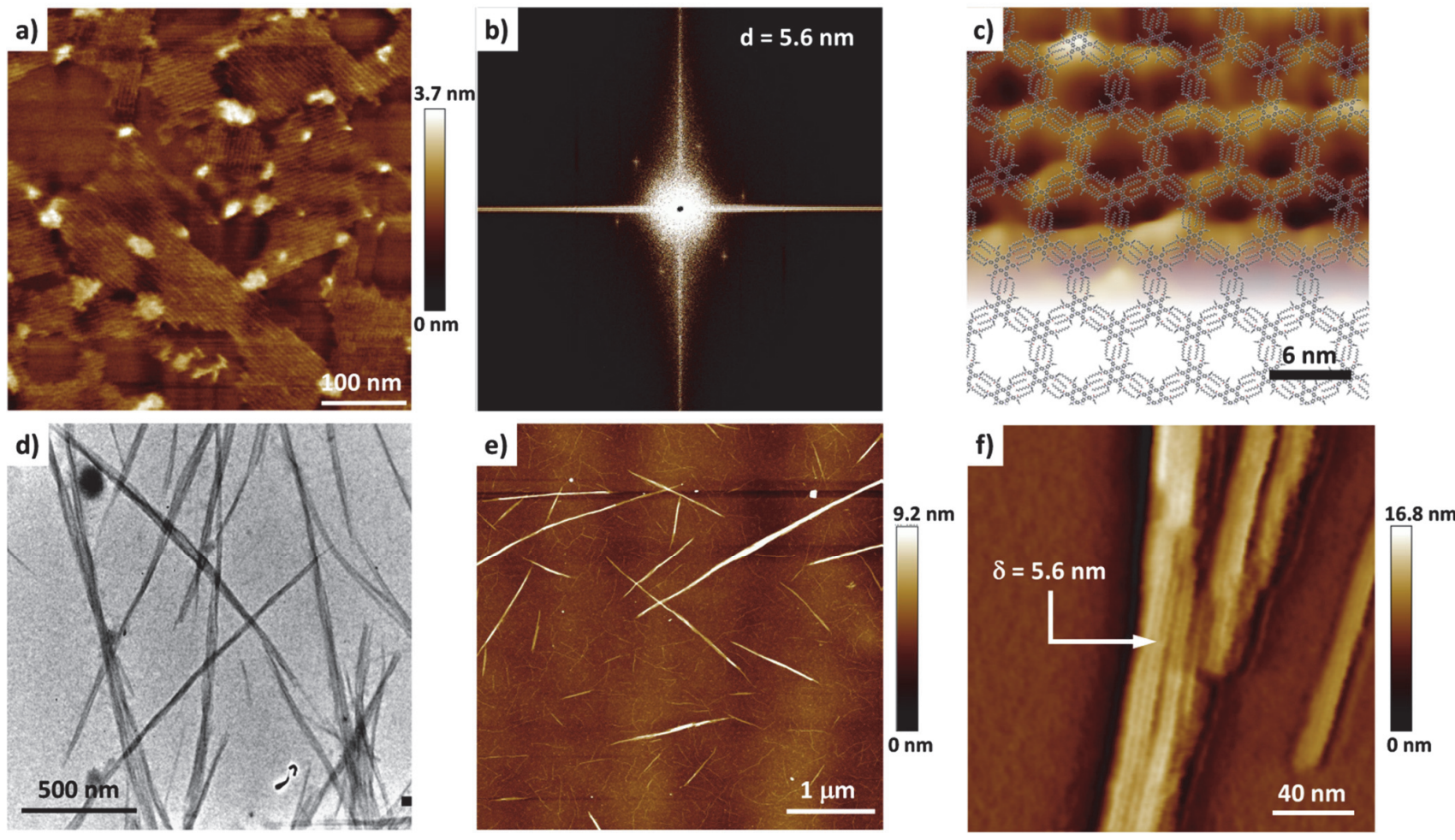

Figure 2. a, c) AFM images of macrocycle $\mathbf{E}$ drop-casted on HOPG from a $5 \mu \mathrm{M}$ acetone solution, and b) the 2D fast Fourier transform of image a) showing a hexagonal pattern with a center to point distance of $5.6 \mathrm{~nm}$; d) TEM and e-f) AFM images of macrocycle $\mathbf{F}$ dropcasted from a $50 \mu \mathrm{M}$ solution in $o$-dichlorobenzene.

In striking contrast, representative (S)TEM, SEM and AFM images obtained from deprotected macrocyle $\mathbf{F}$ in $o$-dichlorobenzene $(o-$ DCB) $(\mathrm{c}=50 \mu \mathrm{M})$ show micrometer-long bundles of fibers (Figure 2d-f and S8a,b), but also individual fibrils by AFM (Figure 2e and $\mathrm{S} 10 \mathrm{a}-\mathrm{c})$. The measured diameter of these latter is comprised between 2.0 and $2.5 \mathrm{~nm}$, which correlates well with the diameter of a single nanotube made of macrocycle $\mathbf{F}$ as obtained by DFT calculations (Figure 3b,e,f). In addition, as shown by AFM within larger bundles, the hierarchical organisation of these individual nanotubes originates from their lateral aggregation with a caracteristic distance of $\approx 5.6 \mathrm{~nm}$ (Figure $2 \mathrm{f}$ and $\mathrm{S} 11 \mathrm{a}, \mathrm{b}$ ), which is equal to that measured for the $2 \mathrm{D}$ hexagonal pattern made of the non-polymerizing macrocycles at a surface (Figure 2c). Therefore, one can argue convincingly that the nanotubes are themselves packed into an hexagonal pattern within these larger fibers as represented in Figure S11c. In addition, as suggested by IR stretching vibrations of both $\mathrm{C}=\mathrm{O}$ and $\mathrm{NH}$ groups,${ }^{28}$ the formation of these structures involves hydrogen bonds taking place between macrocycles within the stacked supramolecular polymers (Figure S7a). Along the same lines, DFT calculations on macrocycle $\mathbf{F}$ (bearing acetamide side-chains instead of nonanoyl ones) revealed that: (a) the most stable conformation of macrocycle $\mathbf{F}$ is flat with a $S_{6}$ symmetry (determined using different functionals and the 6$31 \mathrm{G}(\mathrm{d}, \mathrm{b})$ basis set) (Figure $3 \mathrm{~b}$ and S6), that is in aggrement with the symmetric sets of resonnance signals observed by ${ }^{1} \mathrm{H}$ and ${ }^{13} \mathrm{C}$ NMR (see discussion on possible conformations in SI section 4); (b) these macrocycles can pile up on top of each other as a result of $\pi-\pi$ stacking and hydrogen bonding interactions, and as determined on the supramolecular tetramer optimized by the semi-empirical PM6 method (Figure 3e,f); (c) the typical distances along the supramolecular stacks into the nanotube are: H-bonds $\approx 1.97 \AA$,
$\mathrm{N}(\mathrm{Ar})_{3}-\mathrm{N}(\mathrm{Ar})_{3} \approx 4.85 \AA, \pi-\pi$ stacking of the inner and external phenyl rings $\approx 3.5 \AA$ (Figure $3 \mathrm{f}, \mathrm{g}$ ); (d) in contrast to most supramolecular polymers, the individual units do not tend to twist along the main axis. This absence of helical conformation, in agreement with microscopy experiments, is explained by the propeller shape of each individual triarylamine, which alternate between $\Lambda$ and $\Delta$ forms within a single macrocycle, thus avoiding further supramolecular helicity (Figures $3 \mathrm{~b}, \mathrm{e}$ ). This relative internal conformation also shows that the six strings of H-bonds alternate up and down along the supramolecular nanotube axis, which implies a near zero dipole and a more stable nanotube (Figure $3 \mathrm{f}$ ). Further, we probed the accuracy of these DFT data by performing a wide angle X-ray scattering (WAXS) experiment on the powder obtained from self-assembled F (Figure S12). Satisfingly, the cristalline nature of the self-assembly was confirmed by the presence of Bragg peaks. In particular, the most intense peak at 1.30 $\AA^{-1}$, corresponding to a distance of $4.85 \AA$, is identical to the $\mathrm{N}(\mathrm{Ar})_{3}-\mathrm{N}(\mathrm{Ar})_{3}$ stacking distance between macrocycles found by DFT (Figure 3f). In addition, the broad scattering peak around $1.40-1.50 \AA^{-1}$ corresponds to the packing of the alkyl chains, and the small peak centered at $1.77 \AA^{-1}$ corresponds to the average of aryl $\pi-\pi$ stacking distances around $3.5 \AA$. The WAXS data obtained for the present system are also in full coherence with values already obtained for films of monotriarylamine polymers (TATA in Figure 1a).[25] Altogether, the complementary analyses by NMR and IR spectroscopies, by AFM, TEM, and SEM microscopies, as well as by DFT and WAXS prove that the macrocycles are stacked into axially aligned supramolecular polymers (i.e. nanotubes) (Figure $3 \mathrm{f}$ and S10c), which can then self-assemble in an hexagonal pattern by lateral aggregation (Figure S11c). 
a)

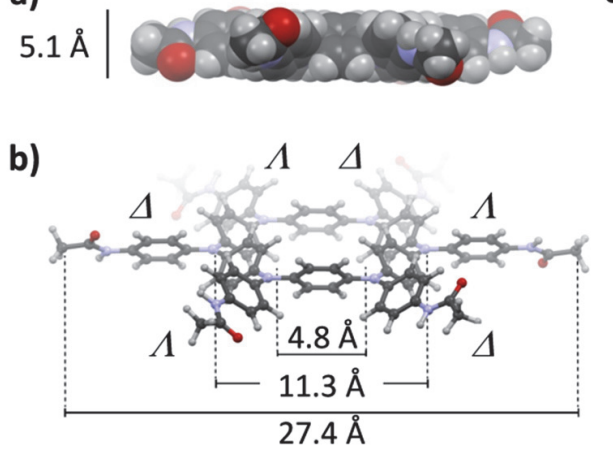

c)

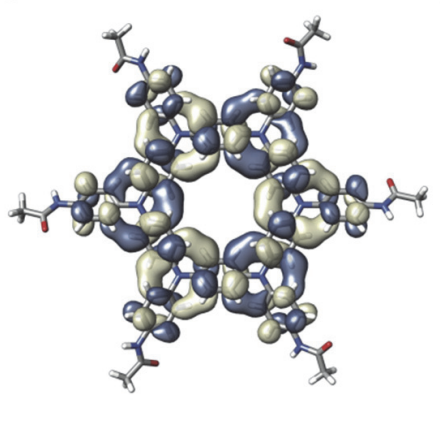

d)

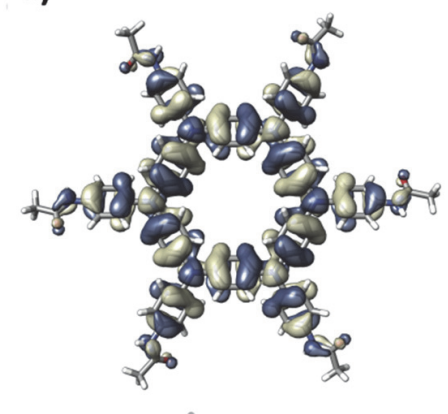

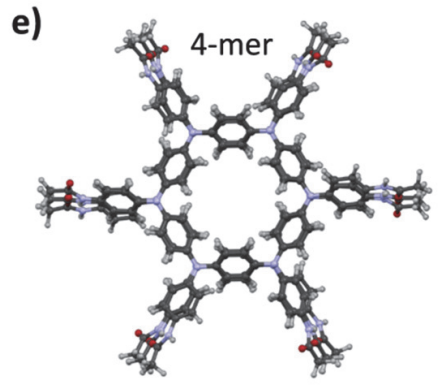

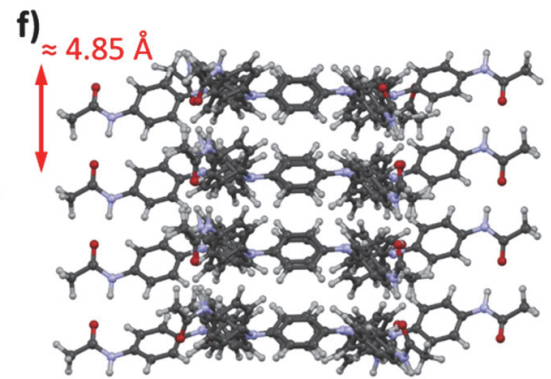

g)

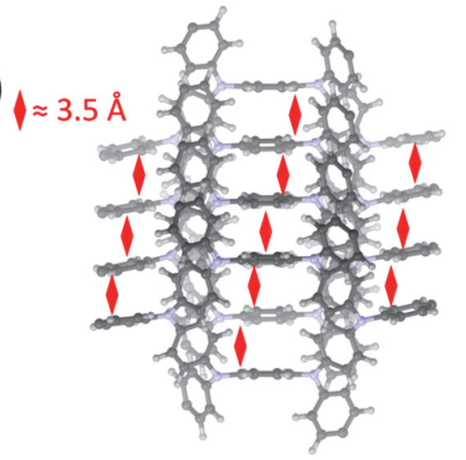

Figure 3. a,b) DFT-optimized structure of compound $\mathbf{F}$ and some characteristic distances, panel b) also shows the alternating $\Delta$ and $\Lambda$ propeller shapes of each individual triarylamine which composes the macrocycle. c,d) Frontier molecular orbitals c) LUMO and d) HOMO calculated by DFT (PBE0/6-31G(d,p)). e) Top view and $\mathbf{f}, \mathbf{g})$ side views of the molecular model of the supramolecular tetramer formed by macrocycle $\mathbf{F}$ as optimized using the semi-empirical PM6 method starting from the DFT-optimized structure of compound $\mathbf{F}$; in f) $4.85 \AA$ corresponds to $\mathrm{N}(\mathrm{Ar})_{3}-\mathrm{N}(\mathrm{Ar})_{3}$ distances and correlates with the indexation of the main Bragg peak in WAXS (Figure S12); and in g) $3.4 \AA$ corresponds to inter-phenyl rings distances between macrocycles (see also WAXS in Figure S12).

We then studied the opto-electronic properties of both macrocycles $\mathbf{E}$ and $\mathbf{F}$, as dilute solutions in $o$-DCB with $10 \%$ DMF, by UV-Vis spectroscopy (Figure 4a). Compared to compound $\mathbf{A}$, a red-shift of $1730 \mathrm{~cm}^{-1}$, concomitant with a 3 -fold increase of the molar absorption coefficient ( $\varepsilon$ ), is observed for molecule $\mathbf{E}$, in agreement with an increase of the number of aromatic units as well as with the conjugated nature of the linkers. The apparent red-shift of $1057 \mathrm{~cm}^{-}$ ${ }^{1}$ (from 331 to $343 \mathrm{~nm}$ ) observed between the protected and the deprotected macrocycle $\mathbf{E}$ and $\mathbf{F}$ is mainly attributed to electronic inductive effects due to the tertiary to secondary amide transformation, in agreement with TD-DFT calculations (see section S4 in ESI). Compared to TATA as a reference (Figure 4a), the shift of the maximum absorption from $327 \mathrm{~nm}$ to $343 \mathrm{~nm}$ (1427 $\mathrm{cm}^{-1}$ ) suggests that improved electronic communication is indeed introduced as previously observed for similar systems. ${ }^{25}$ Further information on the electronic structure of these systems was obtained from fluorescence experiments (Figure 4a). It is apparent that both emissions of $\mathbf{E}$ and $\mathbf{F}$ originate from the core macrocyclic unit because of (a) the similarity of the emission bands, and (b) their red-shifted nature with respect to the observed absorptions. The large Stokes shifts $\left(>9000 \mathrm{~cm}^{-1}\right)$ observed suggest significant differences between the electronic transitions related to the electronic excitation and the radiative excited state. Considering the cyclic nature of these molecules, one can expect that both conformational rearrangement and improved delocalization contribute to the observed Stokes shift. However, the emission intensites of $\mathbf{E}$ and $\mathbf{F}$ are dramatically different. The poor fluorescence of macrocycle F (100 times less emissive) was thought to originate from a classical aggregation-induced quenching mechanism. This explanation was reinforced by measuring the fluorescence emission of $\mathbf{F}$ in pure DMF, as a strongly dissociating solvent, and by the full recovery of the fluorescence intensity (Figure S7b).
The electrochemical properties of both macrocycles $\mathbf{E}$ and $\mathbf{F}$ were then examined by cyclic and square-wave voltammetry in $o-\mathrm{DCB}$, using tetrabutylammonium hexafluorophosphate as supporting electrolyte (Figure 4b). For both compounds, four sequential oxidations were observed between $-0.5 \mathrm{~V}$ and $+0.6 \mathrm{~V}$ against $\mathrm{Fc} / \mathrm{Fc}^{+}$, but with compound $\mathbf{F}$ being oxidized at a lower applied potential than $\mathbf{E}$ for each individual step $(-0.13 \mathrm{~V}$ to $+0.44 \mathrm{~V}$ for $\mathbf{F}$, and $+0.023 \mathrm{~V}$ to $+0.6 \mathrm{~V}$ for $\mathbf{E}$ ), thus suggesting a higher stabilization of the radical cation species for the fully deprotected macrocycle. To better understand the electronic nature of these radical species, we measured the changes in absorption as a function of the applied potential using a thin quartz cuvette equipped with a platinum wire mesh as working electrode (see section S3 in ESI). For both compounds $\mathbf{E}$ and $\mathbf{F}$, a decrease of the absorbance of the neutral species centered around $29850 \mathrm{~cm}^{-1}(\approx 335 \mathrm{~nm})$ was observed at the potential of the first oxidation measured by square-wave voltammetry (Figures 4c,d and S4). This decrease is accompanied for both macrocycles by the appearance of a very broad band around $6700 \mathrm{~cm}^{-1}$ $(1500 \mathrm{~nm})$. This characteristic absorption is clearly assigned to intervalence charge-transfer (IV-CT) bands taking place "through bonds" between conjugated triarylamine units, with a full delocalization of the radical cation over the entire flat macrocycles $\mathbf{E}^{\cdot+}$ and $\mathbf{F}^{*+} .^{17,29,30}$ This measurement is further corroborated by the HOMOLUMO calculations (Figure 3c,d), which show that both orbitals are evenly distributed across the macrocyclic structure. However, further increases of the potential to reach higher oxidation states revealed significant differences between compounds $\mathbf{E}$ and $\mathbf{F}$. For macrocycle $\mathbf{E}$, following an increasing anodic potential up to $\mathbf{E}^{\mathbf{4 ( * )} \text {, }}$ we observed a modest increase of the intensity of the $6700 \mathrm{~cm}^{-1}$ $(1500 \mathrm{~nm})$ band, and its broadening towards shorter wavelengths, together with the appearance of a new absorption band around $12500 \mathrm{~cm}^{-1}(800 \mathrm{~nm})$. 

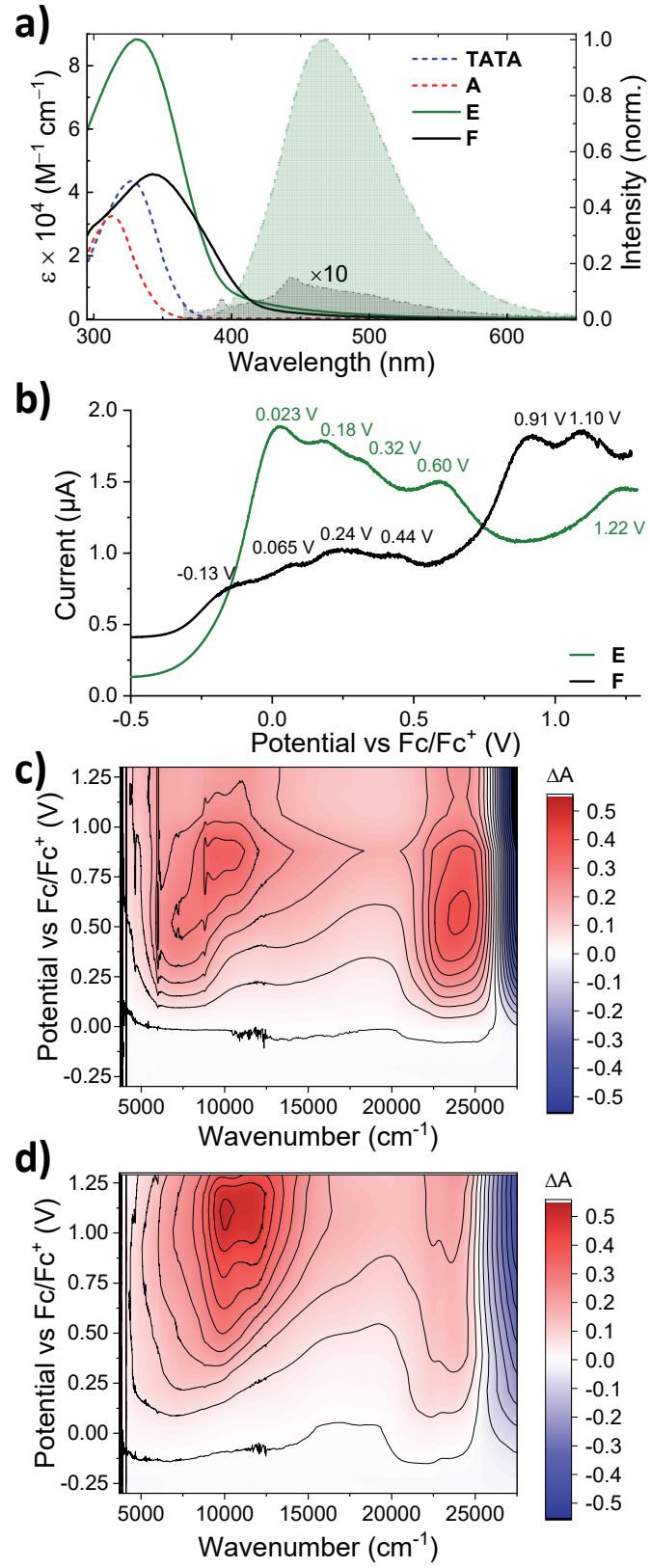

Figure 4. a) UV-Vis absorption spectra of compounds $\mathbf{A}, \mathbf{E}, \mathbf{F}$ and TATA together with emission spectra of compounds $\mathbf{E}$ and $\mathbf{F}$ (green and gray shades, respectively); b) Square-wave voltammograms of macrocycles $\mathbf{E}$ and $\mathbf{F}$ measured at a scan rate of $10 \mathrm{mV} / \mathrm{s}$ and a concentration of $500 \mu \mathrm{M}$ in $o$-DCB and containing $100 \mathrm{mM}$ TBAPF $_{6}$; c-d) UV-Vis-NIR spectroelectrochemical 2D spectra of compound c) $\mathbf{E}$ and d) $\mathbf{F}$ measured at a concentration of $200 \mu \mathrm{M}$ in $o$-DCB containing $100 \mathrm{mM} \mathrm{TBAPF}_{6}$, the $2 \mathrm{D}$ surface corresponds to the differential absorbance considering the $1^{\text {st }}$ measurement as baseline.

This behavior is already known for such macrocycles and shows a decrease of the polaron delocalization as the number of charges increases and repel each other in the macrocycle, up to the formation of localized charges with their characteristic absorption band around $800 \mathrm{~nm} \cdot{ }^{18-20}$ It is also worth noting that beyond $1.0 \mathrm{~V}$, all absorption bands decreased in intensity suggesting that a non-reversible and destructive process takes place. In striking contrast, deprotected macrocycle $\mathbf{F}$ shows, when following the same increas-

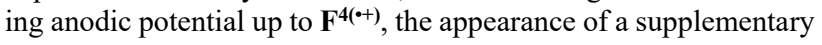

and intense absorption band around $10000 \mathrm{~cm}^{-1}(1000 \mathrm{~nm})$, which is clearly identified above $0.21 \mathrm{~V}$ corresponding to diradical species $\mathbf{F}^{\mathbf{2}(+)}$. This characteristic absorption is assigned to an IV-CT band resulting from "through space" interaction between $\pi-\pi$ stacked triarylamines along the supramolecular nanotube. This interpretation is in full agreement with previous studies based on 1D supramolecular polymers made of single triarylamine units (TATA in Figure 1a). ${ }^{22,25}$ Then, for higher potential and oxidation states (up to $\mathbf{F}^{\mathbf{6}(+)}$ ), the polarons also tend to localize with the appearance of the corresponding band around $12500 \mathrm{~cm}^{-1}(800 \mathrm{~nm})$, as also observed for 1D supramolecular polymers made of TATA. ${ }^{22,25}$ Altogether, these spectroscopic and electrochemical experiments lead to the following conclusions: (a) the macrocyclic compounds $\mathbf{E}$ and $\mathbf{F}$ have a flat $S_{6}$-symmetric conformation leading to sequential oxidations; (b) after a first oxidation, full polaron delocalization occurs within the macrocyclic structure for both $\mathbf{E}^{\cdot+}$ and $\mathbf{F}^{*+}$; (c) after the second oxidation, when repulsions between charges start appearing, the rate of the polaron delocalization tends to decrease within both macrocycles but, for macrocycle $\mathbf{F}$ only, it also tends to take place through space along the stacking direction of its supramolecular structure; (d) this supplementary delocalization mode of polarons in the supramolecular polymer gives a coherent support to the higher stability of their oxidized species compared to the macrocyclic monomers; (e) the dual delocalization regime for the supramolecular polymer is mainly favored for degrees of oxidation comprised between + II and + IV .

\section{CONCLUSION}

In summary, we have described the synthesis of highly functional hexaaza[16]paracyclophanes $\mathbf{E}$ and $\mathbf{F}$ following a convergent pathway. The presence of free amide side chains on macrocycle $\mathbf{F}$ drives its supramolecular polymerization. Spectroscopic, microscopic, and scattering data are consistent with our molecular modelling, and they reveal an axially aligned nanotubular structure with $\pi-\pi$ stacking contacts between all phenyl rings of the macrocycles along their elongation direction. In addition, by using a combination of spectroscopic and electrochemical studies, we have further demonstrated that these supramolecular nanotubes can be oxidized sequentially up to six oxidation states, and we suggest that for degrees of oxidation comprised between +II and + IV, the generated polarons are strongly delocalized both through bonds within the macrocyclic structure, and through space along the supramolecular stacks. Overall, this work describes the first selfassembly of macrocyclic hexaazaparacyclophanes. Beyond their original structures, their first measured opto-electronic properties greatly stimulate our curiosity to reach dual orthogonal electronic delocalization in tubular assemblies, with the potential to access supramolecular solenoids which could be used for the design of entirely novel electroactive nanosystems and materials therefrom.

\section{ASSOCIATED CONTENT}

\section{Supporting Information}

The Supporting Information is available free of charge on the ACS Publications website: Synthetic protocols and characterization of compounds A-F, synthetic routes, protocols and characterization of intermediates leading to compounds $\mathbf{A}$ and $\mathbf{B}$, experimental methods and additional characterizations of the supramolecular polymers by infrared spectroscopy and spectroelectrochemistry, additional AFM images and profiles, WAXS data, DFT calculations and corresponding molecular modelling (PDF).

\section{AUTHOR INFORMATION}

\section{Corresponding Authors}

lehn@unistra.fr 
giuseppone@unistra.fr

\section{Author Contributions}

$\ddagger$ These authors contributed equally.

\section{Notes}

The authors declare no competing financial interests.

\section{ACKNOWLEDGMENT}

This project was supported by a funding from the Laboratory of Excellence for Complex Systems Chemistry (LabEx CSC). F.P. thanks the IdEx program of the University of Strasbourg for a doctoral fellowship. S.S. thanks the ITN DYNANO, PITN-GA-2011289033 for a doctoral fellowship. The authors acknowledge "les plateformes d'analyse des polymères et de microscopie" from the Institut Charles Sadron, and use of the HPC cluster from the Centre de Calcul de l'Université de Strasbourg (CCUS). They also thank Dr. Michel Rawiso and Guillaume Fleith for WAXS experiments.

\section{REFERENCES}

(1) Yashima, E.; Ousaka, N.; Taura, D.; Shimomura, K.; Ikai, T.; Maeda, K. Supramolecular Helical Systems: Helical Assemblies of Small Molecules, Foldamers, and Polymers with Chiral Amplification and Their Functions. Chem. Rev. 2016, 116 (22), 13752-13990. https://doi.org/10.1021/acs.chemrev.6b00354.

(2) Liu, M.; Zhang, L.; Wang, T. Supramolecular Chirality in SelfAssembled Systems. Chem. Rev. 2015, 115 (15), 7304-7397. https://doi.org/10.1021/cr500671p.

(3) De Greef, T. F. A.; Smulders, M. M. J.; Wolffs, M.; Schenning, A. P. H. J.; Sijbesma, R. P.; Meijer, E. W. Supramolecular Polymerization. Chem. Rev. 2009, 109 (11), 5687-5754. https://doi.org/10.1021/cr900181u.

(4) Fouquey, C.; Lehn, J.-M.; Levelut, A.-M. Molecular Recognition Directed Self-Assembly of Supramolecular Liquid Crystalline Polymers from Complementary Chiral Components. Adv. Mater. 1990, $2254-257$. https://doi.org/10.1002/adma.19900020506.

(5) Chen, Z.; Lohr, A.; Saha-Möller, C. R.; Würthner, F. SelfAssembled Pi-Stacks of Functional Dyes in Solution: Structural and Thermodynamic Features. Chem. Soc. Rev. 2009, 38 (2), 564-584. https://doi.org/10.1039/b809359h.

(6) Jain, A.; George, S. J. New Directions in Supramolecular Electronics. Mater. Today 2015, 18 (4), 206-214. https://doi.org/10.1016/j.mattod.2015.01.015.

(7) Moulin, E.; Cid, J.-J.; Giuseppone, N. Advances in Supramolecular Electronics - from Randomly Self-Assembled Nanostructures to Addressable Self-Organized Interconnects. Adv. Mater. 2013, $25 \quad$ (3), 477-487. https://doi.org/10.1002/adma.201201949.

(8) Busseron, E.; Ruff, Y.; Moulin, E.; Giuseppone, N. Supramolecular Self-Assemblies as Functional Nanomaterials.

Nanoscale 2013, 5 (16), 7098-7140. https://doi.org/10.1039/c3nr02176a. Zhang, W.; Jin, W.; Fukushima, T.; Saeki, A.; Seki, S.; Aida, T. Supramolecular Linear Heterojunction Composed of GraphiteLike Semiconducting Nanotubular Segments. Science 2011, 334 (6054), 340-343. https://doi.org/10.1126/science.1210369.

(10) Schenning, A. P. H. J.; Meijer, E. W. Supramolecular Electronics; Nanowires from Self-Assembled $\pi$-Conjugated Systems. Chem. Commun. 2005, No. 26, 3245-3258. https://doi.org/10.1039/b501804h.

(11) Wong, K.-T.; Bassani, D. M. Energy Transfer in Supramolecular Materials for New Applications in Photonics and Electronics. NPG Asia Mater. 2014, 6 (7), e116. https://doi.org/10.1038/am.2014.53.

(12) Armao, J. J.; Rabu, P.; Moulin, E.; Giuseppone, N. Long-Range Energy Transport via Plasmonic Propagation in a Supramolecular Organic Waveguide. Nano Lett. 2016, 16 (4), 2800-2805. https://doi.org/10.1021/acs.nanolett.6b00581.

(13) Armao, J. J.; Domoto, Y.; Umehara, T.; Maaloum, M.; Contal,
C.; Fuks, G.; Moulin, E.; Decher, G.; Javahiraly, N.; Giuseppone, N. Supramolecular Organic Nanowires as Plasmonic Interconnects. ACS Nano 2016, 10 (2), 2082-2090. https://doi.org/10.1021/acsnano.5b06294.

Babu, S. S.; Praveen, V. K.; Ajayaghosh, A. Functional $\pi-$ Gelators and Their Applications. Chem. Rev. 2014, 114 (4), 1973-2129. https://doi.org/10.1021/cr400195e.

Stupp, S. I.; Palmer, L. C. Supramolecular Chemistry and SelfAssembly in Organic Materials Design. Chem. Mater. 2014, 26 (1), 507-518. https://doi.org/10.1021/cm403028b.

(16) González-Rodríguez, D.; Schenning, A. P. H. J. HydrogenBonded Supramolecular $\pi$-Functional Materials. Chem. Mater. 2011, 23 (3), 310-325. https://doi.org/10.1021/cm101817h.

(17) Ito, A.; Yokoyama, Y.; Aihara, R.; Fukui, K.; Eguchi, S.; Shizu, K.; Sato, T.; Tanaka, K. Preparation and Characterization of NAnisyl-Substituted Hexaaza[16]Paracyclophane. Angew. Chem. Int. Ed. 2010, 49 (44), 8205-8208. https://doi.org/10.1002/anie.201002165.

(18) Yang, T.-F.; Chiu, K. Y.; Cheng, H.-C.; Lee, Y. W.; Kuo, M. Y.; $\mathrm{Su}$, Y. O. Studies on the Structure of N-Phenyl-Substituted Hexaaza[16]Paracyclophane: Synthesis, Electrochemical Properties, and Theoretical Calculation. J. Org. Chem. 2012, 77 (19), 8627-8633. https://doi.org/10.1021/jo301436g.

(19) Kulszewicz-Bajer, I.; Maurel, V.; Gambarelli, S.; Wielgus, I.; Djurado, D. Ferromagnetic Spins Interaction in Tetraaza- and Hexaazacyclophanes. Phys. Chem. Chem. Phys. 2009, 11 (9), 1362-1368. https://doi.org/10.1039/b814957g.

(20) Skorka, L.; Kurzep, P.; Chauviré, T.; Dubois, L.; Mouesca, J.-M.; Maurel, V.; Kulszewicz-Bajer, I. High-Spin Polymers: Ferromagnetic Coupling of $\mathrm{S}=1$ Hexaazacyclophane Units up to a Pure S $=2$ Polycyclophane. J. Phys. Chem. B 2017, 121 (16), 4293-4298. https://doi.org/10.1021/acs.jpcb.7b01531.

(21) Ito, A. Macrocyclic Oligoarylamines as Hole- and SpinContaining Scaffolds for Molecule-Based Electronics. J. Mater. Chem. C 2016, 4 (21), 4614-4625. https://doi.org/10.1039/C6TC00973E.

(22) Moulin, E.; Armao, J. J.; Giuseppone, N. Triarylamine-Based Supramolecular Polymers: Structures, Dynamics, and Functions. Acc. Chem. Res. 2019, $52 \quad$ (4), 975-983. https://doi.org/10.1021/acs.accounts.8b00536.

(23) Busseron, E.; Cid, J.-J.; Wolf, A.; Du, G.; Moulin, E.; Fuks, G.; Maaloum, M.; Polavarapu, P.; Ruff, A.; Saur, A.-K.; et al. LightControlled Morphologies of Self-Assembled TriarylamineFullerene Conjugates. ACS Nano 2015, 9, 2760-2772. https://doi.org/10.1021/nn506646m.

(24) Ellis, T. K.; Galerne, M.; Armao, J. J.; Osypenko, A.; Martel, D.; Maaloum, M.; Fuks, G.; Gavat, O.; Moulin, E.; Giuseppone, N. Supramolecular Electropolymerization. Angew. Chem. Int. Ed. 2018, $57 \quad$ (48), $15749-15753$. https://doi.org/10.1002/anie.201809756.

(25) Armao, J. J.; Maaloum, M.; Ellis, T.; Fuks, G.; Rawiso, M.; Moulin, E.; Giuseppone, N. Healable Supramolecular Polymers as Organic Metals. J. Am. Chem. Soc. 2014, 136 (32), 1138211388. https://doi.org/10.1021/ja5044006.

(26) Ishow, E.; Camacho-Aguilera, R.; Guérin, J.; Brosseau, A.; Nakatani, K. Spontaneous Formation of Complex Periodic Superstructures under High Interferential Illumination of SmallMolecule-Based Photochromic Materials. Adv. Funct. Mater. 2009, 19 (5), 796-804. https://doi.org/10.1002/adfm.200801497. Singh, S. B. Total Synthesis of Flutimide, a Novel Endonuclease Inhibitor of Influenza Virus. Tetrahedron Lett. 1995, 36 (12), 2009-2012. https://doi.org/10.1016/0040-4039(95)00214-W.

(28) Simic, V.; Bouteiller, L.; Jalabert, M. Highly Cooperative Formation of Bis-Urea Based Supramolecular Polymers. J. Am. Chem. Soc. 2003, $125 \quad$ (43), 13148-13154. https://doi.org/10.1021/ja037589x.

(29) Lambert, C.; Nöll, G. Intervalence Charge-Transfer Bands in Triphenylamine-Based Polymers. Synth. Met. 2003, 139 (1), 5762. https://doi.org/10.1016/S0379-6779(02)01250-X.

(30) Heckmann, A.; Lambert, C. Organic Mixed-Valence Compounds: A Playground for Electrons and Holes. Angew. Chem. Int. Ed. 2012, $51 \quad$ (2), 326-392. https://doi.org/10.1002/anie.201100944. 
TABLE OF CONTENTS ARTWORK

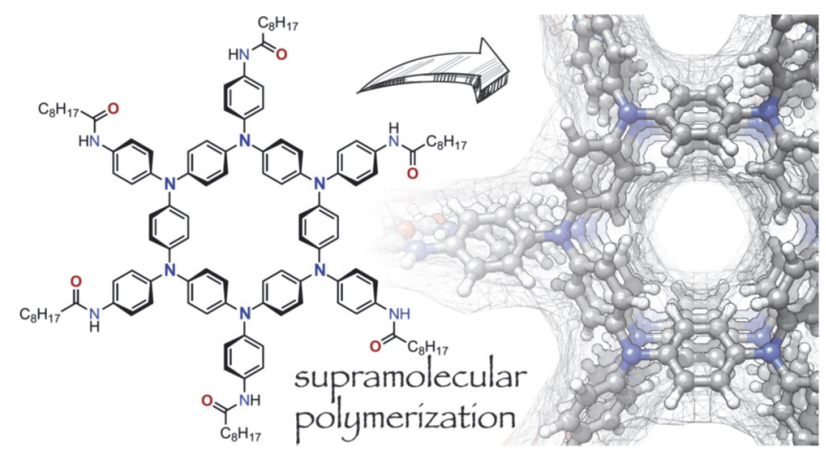

